\title{
Spontaneous Renal Artery Dissection with Renal Infarct
}

\author{
Canan Altay (D), Ișıl Basara Akın (1), Mustafa Seçil (1) \\ Department of Radiology, Dokuz Eylül University School of Medicine, İzmir, Turkey
}

ORCID iDs of the authors: C.A 0000-0003-04I7-7770; I.B.A.0000-0002-0786-1490; M.S. 0000-000I-7350-2002.

Cite this article as: Altay C, Basara Akın I, Seçil M. Spontaneous Renal Artery Dissection with Renal Infarct. Cyprus J Med Sci 2020; 5(2): 187-8.

Dear Editor,

A 5l-years-old woman was admitted to emergency service with left flank pain and nausea for the last few hours. She denied history of the renal stone disease. Abdominal examination revealed tenderness of left flank region. $V i t a l$ signs were insignificant. Microscopic haematuria was observed on the urine analysis. Leucocyte count was 9530/mm3. Total triglyceride and cholesterol levels were high than normal values. The abdominal US was normal. Contrast-enhanced abdominal computed tomography (CT) revealed irregular and long segment stenotic left renal artery due to spontaneous dissection and wedge-shaped infarcts at the lower pole of the left kidney (Figure I). 3D volume rendering reformatted CT image revealed a disconnected focal area on the left renal artery due to dissection (stippled red arrow). The proximal segment of the left renal artery (yellow arrow) were normal on the reformatted images (Figure 2). The patient subsequently underwent endovascular treatment. The patient was discharged on the $3^{\text {rd }}$ day after treatment with no further symptoms or complications. The patient's consent was assessed.

Renal artery dissection usually occurs due to secondary to iatrogenic or traumatic injury. However, spontaneous renal artery dissection (SRAD) is a rare, and it is often unrecognized entity but remains a radiological finding that all clinicians should be aware of. The incidence of SRAD is very rare; approximately 200 cases of SRAD have been published in the English literature, especially in the fourth to the sixth decade with a marked male predominance (I, 2). Approximately I0$15 \%$ of all cases have bilaterally renal artery dissection.

Progressive renovascular hypertension, changes in renal function, haematuria and symptoms of kidney infarction are frequent symptoms of SRAD; however, a most frequent symptom is sudden onset flank pain and renal colic symptoms in patients with SRAD. The patient we present had a sudden onset of flank pain and nausea, which was similar to literature. Clinically differential diagnosis of SRAD is difficult and include renal stone disease and pyelonephritis (3). Ultrasound is
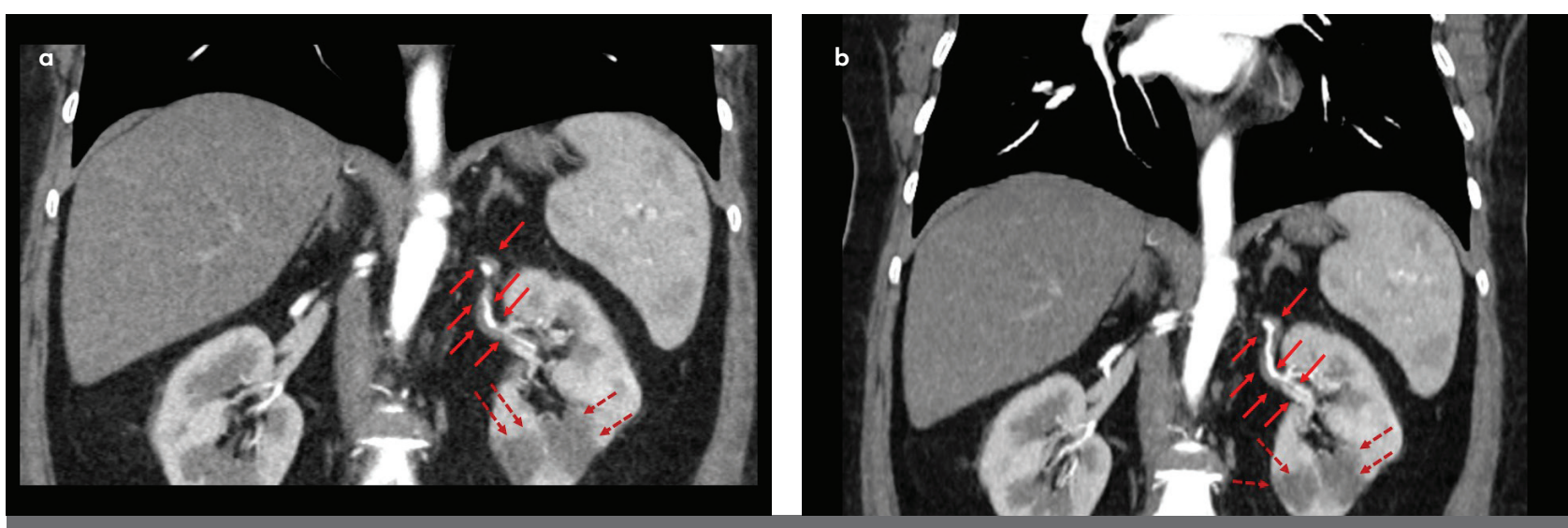

FIGURE I. Irregular and long segment stenotic left renal artery due to spontaneous dissection and wedge-shaped infarcts 


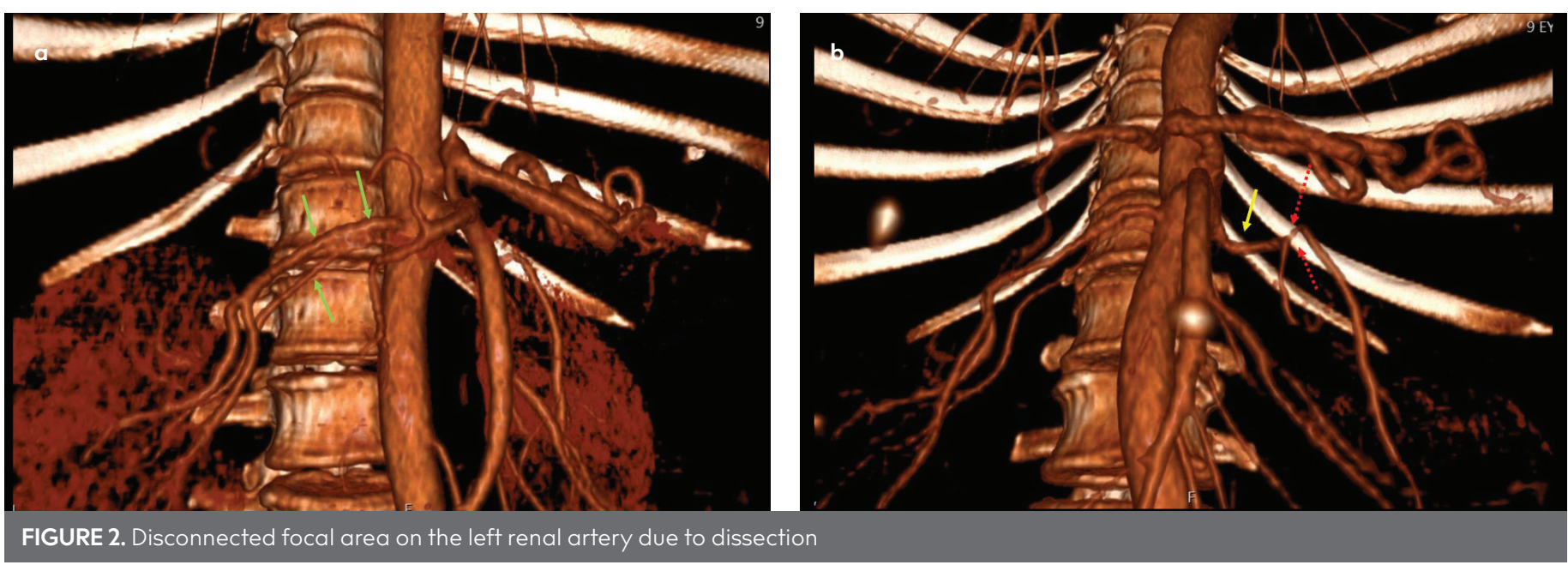

the first imaging method for flank pain, whereas it has a limited role for diagnoses in renal artery dissection. IV contrast-enhanced computed tomography (CT) has a diagnostic accuracy rate of up to $100 \%$ in renal infarcts and renal artery dissection (4). On CT images, renal infarct areas reveal wedge-shaped hypodense areas on the axial CT images. Peri-renal fat stranding can also observe around the infarcted renal parenchyma. On the contrast-enhanced CT images, diffuse wall thickening of the renal artery due to SRAD and narrowing at the renal artery lumen may also help to establish a final diagnosis (4).

Although the majority of patients with SRAD may be treated conservatively with anticoagulant therapy (5), endovascular treatment (stenting or coiling) is the important non-invasive treatment alternative in the patients who are hemodynamically unstable $(6,7)$. As a result, SRAD is a very rare vascular disorder and most complicated with renal infarct. Diagnosis is mostly delayed because most patients have insignificant symptoms. Contrast-enhanced abdominal CT is significant for quick and definitive diagnosis.

Informed Consent: Written informed consent was obtained from patient who participated in this study.

Peer-review: Externally peer-reviewed.

Author Contributions: Concept - C.A.; Design - C.A.; Supervision - M.S.; Materials - I.B.A.; Data Collection and/or Processing - C.A., I.B.A.; Anal- ysis and/or Interpretation - C.A.; Literature Search C.A.; Writing Manuscript - C.A.; Critical Review - M.S.

Conflict of Interest: Authors have no conflicts of interest to declare.

Financial Disclosure: The authors declared that this study has received no financial support.

\section{REFERENCES}

I. LaCombe M. Isolated spontaneous dissection of the renal artery. $J$ Vasc Surg 200l; 33(2): 385-91. [Crossref]

2. Edwards BS, Stanson AW, Holley KE, Sheps SG. Isolated renal artery dissection, presentation, evaluation, management, and pathology. Mayo Clin Proc 1982; 57: 564-71.

3. Kanofsky JA, Lepor H. Spontaneous Renal Artery Dissection. Rev Urol 2007; 9: 156-60.

4. Renaud S, Leray-Morague`s H, Chenine L, Canaud L, Vernhet-Kovacsik $\mathrm{H}$, Canaud B. Spontaneous renal artery dissection with renal infarction. Clin Kidney J 2012; 5(3): 26I-4. [Crossref]

5. Misrai V, Peyromaure M, Poiree S, Marteau V, Laurian C. Spontaneous dissection of branch renal artery - is conservative management safe and effective? J Urol 2006; 176(5): 2125-9. [Crossref]

6. Pellerin O, Garcxon P, Beyssen B, Raynaud A, Rossignol P, Jacquot C, et al. Spontaneous renal artery dissection: long-term outcomes after endovascular stent placement. J Vasc Interv Radiol 2009; 20(8): 1024-30. [Crossref]

7. Șahin S, Okbay M, Çınar B, Uzunlulu N. Wide-necked renal artery aneurysm: endovascular treatment with stent-graft. Diagn Interv Radiol 2007; 13: 42-5. 